\title{
Remote Monitoring Data Acquisition System to Alleviate Deforestation
}

\author{
J.Senthil Kumar ${ }^{1}$, A.Uma Sankari ${ }^{2}$, R.Jeevitha ${ }^{3}$ \\ Assistant Professor, ECE Department, Mepco Schlenk Engineering College, Sivakasi, India ${ }^{1}$ \\ Final year, ECE Department, Mepco Schlenk Engineering College, Sivakasi, India ${ }^{2,3}$
}

\begin{abstract}
Being emphatically leveraged by the adverse impact of the deforestation, especially the cutting of trees and the detritus mixed in air due to the burning of trees that had lead to the extermination of the fragile resources. The information gathered through our security system would help the ministry of Environment and Forests in accounting the national resources and the rate at which they are being consumed. In addition, the information can help in the demarcation of forest land inhibited by human beings which has become a major issue. And in the real-time, monitoring the illegal logging practices which have been a major concern for several decades. Deforestation has caused a lot of environmental disturbances and the current trend is continuing downhill. The burgeoning fields of trade and industry and the booming metropolis are causing a detrimental effect on the whole.
\end{abstract}

Keywords: Temperature Sensor, PIR sensor, Vibration Sensor.

\section{INTRODUCTION}

Currently as there is no gadget to estimate the extinction of natural resources, therefore by the above axiom, we were outraged to build this monitoring system, which serves as a helpmate for the conservancies that are available to uproot the hardship deforestation.

In addition to deforestation it also helps to alleviate hunting of animals. Till date, the steps that are taken to eradicate deforestation is only planting of tree saplings. So our proposal depicts the method to eradicate deforestation through the use of sensors such as temperature, vibration and PIR. Such an electronic tool would help our world to become an influential player at the crucial climatic change.

\section{PROBLEM STATEMENT:}

The World Resources Institute estimates that most of the world's remaining indigenous forest about 22 percent of its original amount.

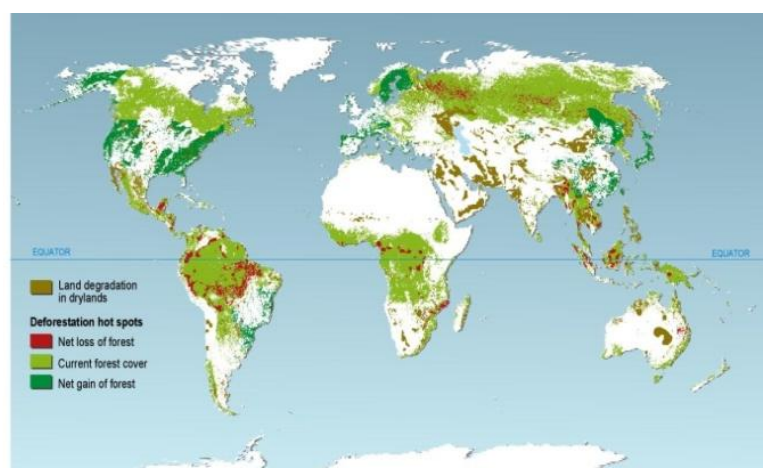

SATELLITE IMAGE:

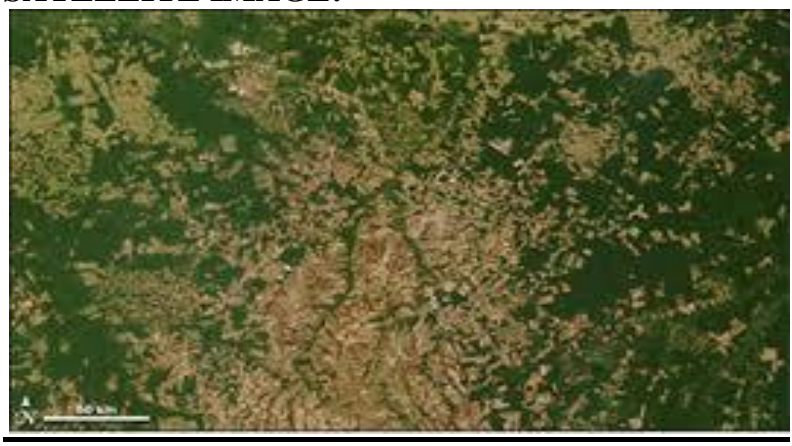

\section{TECHNICAL BACKGROUND:}

The two main papers that we referred for this social issue mainly depends on Geographic Information System (satellite) in order to get the forest land coverage details. So we were greatly outraged to bring this alleviation mechanism into embedded domain.

\section{II.PROPOSED SOLUTION}

TOP LEVEL BLOCK DIAGRAM:

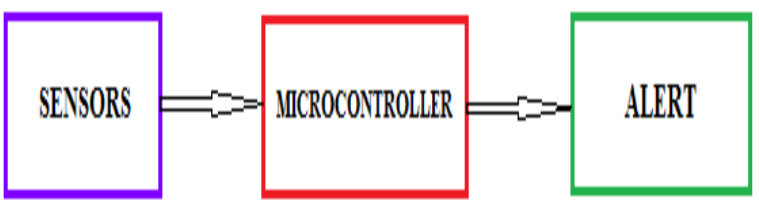

Fig. 1 Functional block diagram

Fig.1 depicts the method to eradicate deforestation through the use of sensor hub out of which the PIR sensor senses the human/animal intrusion inside the forest, the vibration sensor senses the vibration produced by cutting the trees and finally the temperature sensor senses the temperature rise that is caused by firing of trees by the intruder. For every sensor the output of it is compared our security system is used to serve forest area even less than $25 \mathrm{~m}$ whereas Satellite technology is required for the determination of tropical deforestation. Due to the inaccessibility of many areas and the impracticability of aircraft-based survey methods. 
with a threshold value and the alert is given via GSM as Initially the temperature of the forest is measured and messages and the corresponding location of the intruder is given by GPS.

\section{BLOCK DIAGRAM:}

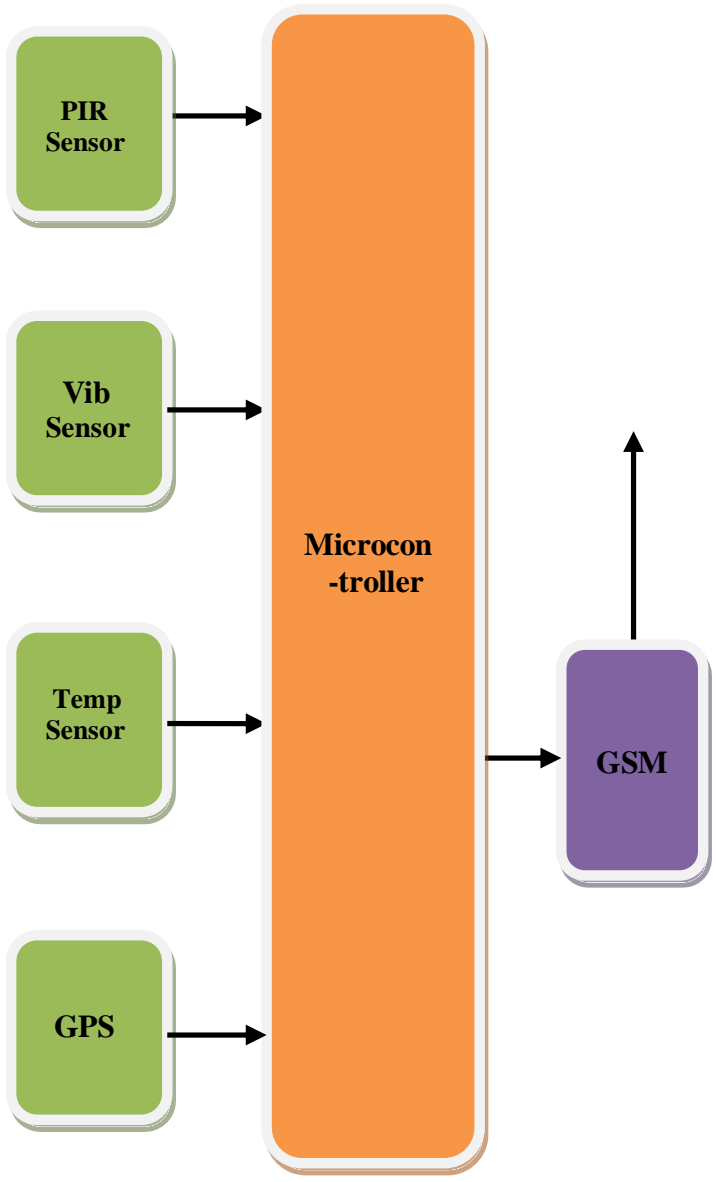

\section{III.IMPLEMENTATION}

WORKING:

The proposal depicts the method to eradicate deforestation through the use of sensor hub, GPS, GSM etc, out of which the PIR sensor senses the human intrusion inside the forest, the vibration sensor senses the vibration produced by cutting the trees and finally the temperature sensor senses the temperature that is fired by the intruder.

Among all these if anyone of the means is sensed, the GPS module gets enabled and the corresponding position and time will be sent to the personnel in-charge along with message inscribed in the GSM.

\section{TEMPERATURE SENSOR:}

Initially the temperature of the forest is measured and recorded. During the firing of the trees the temperature will rise tremendously beyond the normal recorded temperature. This is being continuously monitored by the sensor, once the temperature rise is detected it can be confirmed that firing is being done. This will also act as the indicating measure in case of forest fire too. recorded. During the firing of the trees the temperature will rise tremendously beyond the normal recorded temperature.

This is being continuously monitored by the sensor, once the temperature rise is detected it can be confirmed that firing is being done. This will also act as the indicating measure in case of forest fire too.

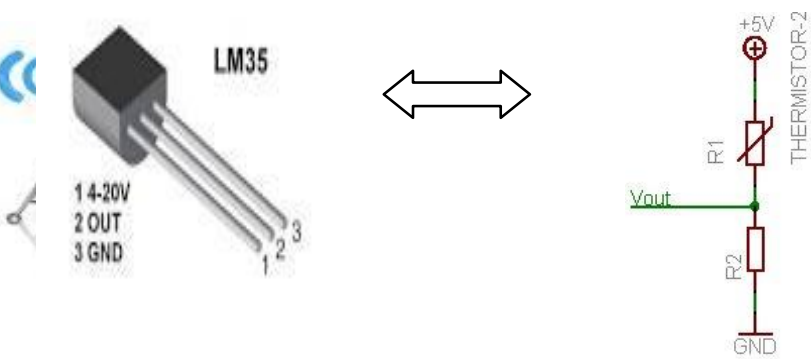

Fig. 2(a) LM35 Temperature sensor

Fig. 2(b) Internal circuitry

\section{PIR SENSOR:}

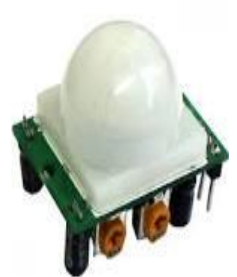

Fig.3(a) PIR sensor

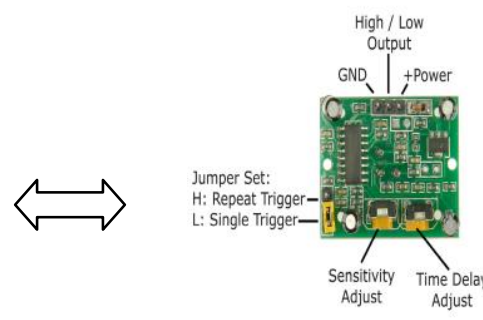

Fig. 3(b) Internal circuitry
The pyroelectric sensor is made of a crystalline material that generates a surface electric charge when exposed to heat in the form of infrared radiation.

When the amount of radiation striking the crystal changes, the amount of charge also changes and can then be measured with a sensitive FET device built into the sensor.

The sensor is also able to discriminate the heat radiation of an animal of $55 \mathrm{lbs}$ and that of a human's. This drastically reduces the chance of false detection in the detection area.

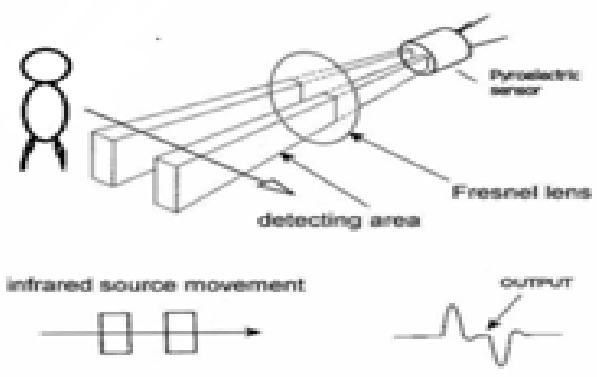

Fig. 4(a) Shows the crossing of human being in the field area of PIR sensor 

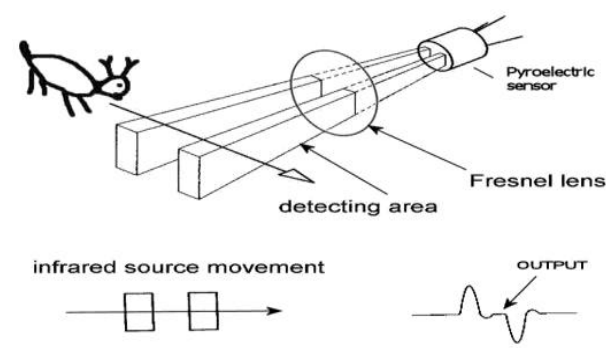

Fig. 4(b) Shows the crossing of an animal in the field area of PIR sensor

\section{VIBRATION SENSOR:}

The deforestation can also be accomplished by cutting the trees down. Vibration Sensor collects 3 dimensional orientation of the vibration signal in real-time, and compares it with the vibration amplitude that is already set. Once exceeded, it would be associated with the output switching signal to trigger GPS.

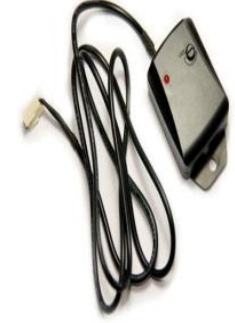

Fig. 5(a) Vibration sensor

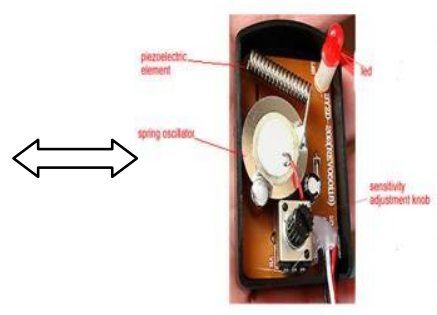

Fig. 5(b) Internal circuitry
GPS:

A series of standard NMEA format messages are provided to give position, satellite information, time, etc., of a particular place in the forest. The module can then be easily connected directly to a microcontroller to record this information.

\section{GSM:}

A user-defined SMS message is sent to pre-configured mobile phone numbers when a pre-defined alarm condition happens. These pre-configured mobile phone numbers can belong to technicians or engineers who are responsible in handling the corresponding alarms. With the aid of this GSM Controller, the alarm condition brings attention to in-charge personnel immediately.

\section{Temperature Sensor:}

\section{IV.SAMPLE OBSERVATIONS}

\begin{tabular}{|c|c|}
\hline Temp ( in Celsius) & HEX value \\
\hline 25.7 & 0B-0D \\
\hline 26.9 & 0E-0F \\
\hline
\end{tabular}

PIR Sensor:

\begin{tabular}{|l|c|}
\hline \multicolumn{1}{|c|}{ Human Presence } & A7-A9 \\
\hline $\begin{array}{l}\text { No Human, Animal } \\
\text { Presence }\end{array}$ & 00 \\
\hline
\end{tabular}

\section{Vibration Sensor:}

\begin{tabular}{|c|c|}
\hline Vibration & 08 \\
\hline No Vibration & E3-E9 \\
\hline
\end{tabular}

\section{V.RESULTS OBTAINED}

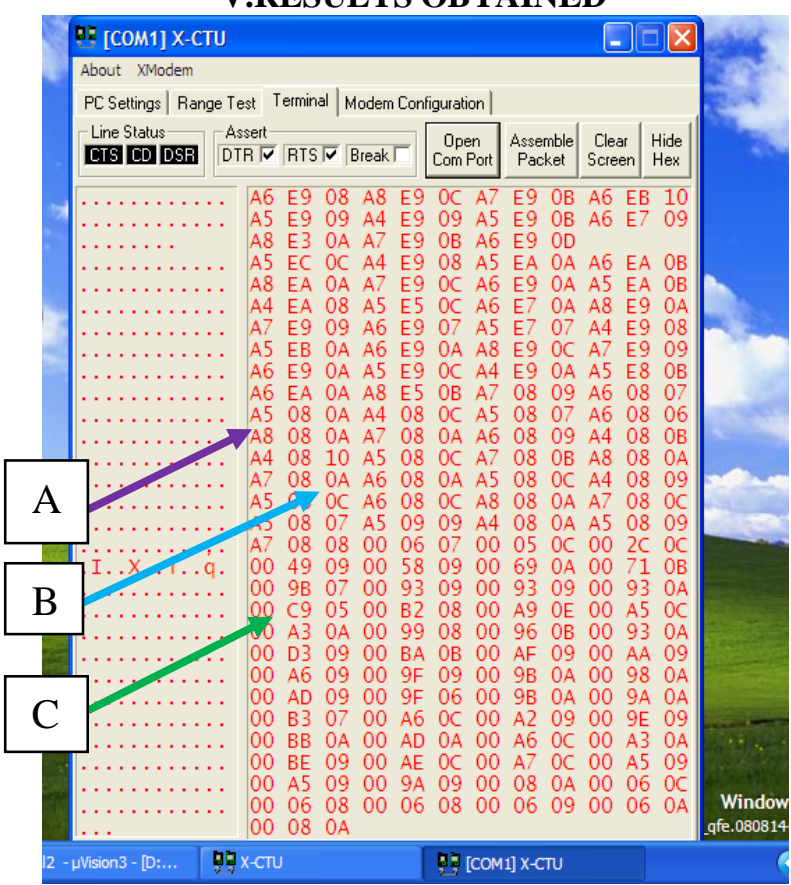

\section{A- PIR Sensor \\ B- Temperature Sensor \\ C- Vibration Sensor}

\section{VI.CONCLUSION}

Our gadget serves as a remote monitoring device for the interior areas of the forest which cannot be covered under the satellite surveillance. It will also help to protect the trees in the forest that decrease erosion, provides carbon sequestration and temperature control. It is also a boon to embedded systems. Compared to satellite surveillance this will be very inexpensive. Only thing is that it should be hidden from the intruder.

\section{REFERENCES}

1. Kumar, P., Rani, M., Pandey, P. C., Majumdar, A. and Nathawat,M. S, Monitoring of deforestation and forest degradation using remote sensing and GIS, Vol.8,no.2, 2011

2. C. J. Tucker and J. R. G. Townshend, A Method to Estimate Land Cover Changes by using CBERS2-CCD Data and GIS Data, Vol.4, 2013

3. Arvidson, T., J. Gasch, and S.N. Goward, Landsat 7's Long Term Acquisition Plan- An innovative approach to building a global archive. Remote Sensing of Environment, 78(1-2), 13-26,2001.

4. Asner, G.P., 2001: Cloud cover in Landsat observations of the Brazilian Amazon. International Journal of Remote Sensing, 22, 3855-3862. 